\title{
Strawberries hybrid drying combining airflow, dic technology and intermittent microwaves
}

\begin{abstract}
Amami, E. ${ }^{\text {a,b,c*; }}$;esombes, C. ${ }^{\text {; }}$ Kechaou, N..$^{\text {; }}$ Allaf, K. ${ }^{\mathrm{c}}$
${ }^{a}$ Université de Manouba. Laboratoire de recherche « Physiopathologies, Alimentations et Biomolécules (PAB) ». Institut Supérieur de Biotechnologie Sidi Thabet 2020, Ariana, Tunisie.

bUniversité de Tunis El Manar. Institut Supérieur des Sciences Biologiques Appliquées de Tunis, Unité de recherche «Chimie des matériaux et de l'Environnement », 9, rue Zouhair Essafi Tunis 1006 Tunisia. 'University of La Rochelle, Laboratory of Engineering Science for Environment (LaSIE UMR 7356 CNRS), Avenue Michel Crépeau, 17042 La Rochelle, France.

dUniversité de Sfax. Groupe de recherche en Génie des Procédés Agroalimentaires. Ecole Nationale d'Ingénieurs de Sfax (ENIS), Sfax, Tunisia.
\end{abstract}

*E-mail of the corresponding author: ezzeddineamami@yahoo.fr

\begin{abstract}
1-cm strawberry slices were partially airflow-dried at $50^{\circ} \mathrm{C}$, to reach $0.25 \mathrm{~g}$ $\mathrm{H} 2 \mathrm{O} / \mathrm{g} \mathrm{db}$. Optimized DIC treatment was performed at $350 \mathrm{kPa}$ for $10 \mathrm{~s}$. The final drying stage of these DIC-expanded slices was achieved from 0.25 to 0.1 g H2O/g db (dry basis) using intermittent Pulsed Micro-Wave Drying PMWD to prevent from the paradoxical step of coupled conduction heat transfer with deep generation and transfer of vapor. PMWD was defined at constant $100 \mathrm{~W}$ for $3.25 \pm 0.05 \mathrm{~g}$ with constant active time ton maintained at $2 \mathrm{~s}$, and tempering time toff ranged between 2 and 10 s, or with a continuous way. By decreasing both energy consumption and total drying time of DIC-expanded slices using intermittent microwave, the whole cost significantly decreased to be much lower than the conventional MWD drying, with a great increasing of the quality.
\end{abstract}

Keywords: Airflow Drying; Instant Controlled Pressure-Drop DIC; SwellDrying; Pulsed Micro-Wave Drying; Physical and Chemical Characteristics.. 


\section{Introduction}

Dehydration of strawberry aims at extending product availability while preserving nutritional components, and gains a noticeable increase [1]. Major disadvantages of airflow drying of strawberry are lengthy drying time and low energy efficiency $[2,3]$. The three most crucial aspects of airflow drying resides in 1 / a first stage of superficial evaporation of water allowing the material core to have low temperature (Wet-bulb temperature), which implies ample preservation of nutritional contents (color, antioxidants...), 2/ a shrinkage of the low-temperature glass-transition polymers; this leads to a weaker effective diffusivity of water, and $3 /$ a final paradoxical stage of coupled heat conduction and Fick vapor diffusion transfer. This last generates a high-temperature/long-time stage source of the most part of degradation of the active molecules. The quality of the final dried product and its cost mainly depend on the final stage of drying [4].

The swell-drying of strawberry for crispy, high nutritional quality was defined by Alonzo-Macias et al. (2012) [5] as an Instant Controlled Pressure Drop DIC texturing treatment following a first stage of airflow drying. DIC targets at remedying the product shrinkage via a controlled expansion improving process kinetics and final quality of dried products. This operation doesn't reduce the famous final paradoxical stage of airflow drying, which occurs when the main evaporation process occures within the matrix. Al Haddad et al. 2008 [4] were the first researchers to propose to remedy such a paradoxical stage drying through a distinct final stage of drying using Darcy process issued from Micro-Wave drying, overheated steam drying, or Multi-Flash Autovaporization MFA drying.

Thus Al Haddad et al. 2008 [4] were the only researchers who experimentally defined for green apple strips and sweet potato slices an efficient and economic three-stage drying process of hot air drying combined to a DIC texturing stage, and finally using microwave assisted ambient temperature airflow dehydration. In their study, each drying kinetic was carried out through $720 \mathrm{~W}$ power and different number of cycles. Each cycle consisted in subjecting the products to microwave assisted by ambient temperature air for 30 seconds and then sweeping the products with only air at ambient temperature for one minute. The use of MW may ensures a deep and almost uniform heating way implying the same required orientation of the both gradients of temperature $\left(\mathrm{T}_{\mathrm{i}}>\mathrm{T}_{\mathrm{s}}\right.$ for heating) and vapor pressure $\left(\mathrm{p}_{\mathrm{vi}}>\mathrm{p}_{\mathrm{vs}}\right)$ between the core and the superficial zone of the product. It should be an effective manner to overcome the paradoxical stage improving thus the drying kinetics.

Microwaves are an attractive source of thermal energy, generate volumetric internal heating within the product, increasing the internal total pressure (air+vapor) [6]. Microwave drying using continuous microwave energy is rapid and energy-efficient compared to conventional airflow drying [7]. However, the too rapid mass transport caused by MW power and uneven temperature and moisture distribution may cause overheat in the sample, provoking deep dark-point tissue damage, and/or undesirable changes in the food texture [8]. Some of the limitations of single MW drying can be overcome by combining MW energy with conventional heating or by using microwave energy in a pulsed manner in order to maximize drying efficiency possibly improving the product quality [7].

Moreover, intermittent Pulsed Microwave Drying PMWD operation has proven itself a good method to avoid uneven over-heating by allowing redistribution of temperature and water to diffuse through 
the sample during power-off time [9]. PMWD has to be defined and performed in order to improve both drying process performance (kinetics, etc.) and preserve swell-dried strawberry quality attributes (color, antioxidant content, etc.). This study would be a basis to extend this operation to other fragil fruits, and technically support the industrial scale of final products for various applications (baby foods, nutraceutics...) to make them commercially available.

To define an efficient and economic hybrid drying process, this work compiled 1/ a first conventional stage airflow drying AFD, 2/ a second stage of well-controlled texturing process of Instant Controlled Pressure-Drop DIC, and 3/ a microwave dehydration (MWD) whose driving force is the gradient of the total pressure of Darcy's permeability, which advantageousely replaces Fick's diffusion mass-transfer. Two features prevent thermal MW energy from accumulating in the material through the removal of the generated vapor, by $1 /$ replacing the too compact AFD structure by porous swell-dried materials; the high porosity induces a high permeability of the vapor, and 2/ using a pulsed PMWD.

Therefore, using the intermittet microwave drying after SD, this current work aimed to 1 / examine the effectiveness and optimize the PMWD applied in early stage of drying from the point of view of overall final quality of dried slices of strawberry, a heat sensitive fruit, and 2/ evaluate the effectiveness of intermittent PMWD drying at optimized conditions ( $t_{\text {on }}$; toff) compared with continuous microwave, airflow drying and freeze-drying (FD) in terms of drying kinetics and visual attributes of dried rehydrated SD strawberries.

\section{Materials and Methods}

\subsection{Fresh materials}

Fresh strawberries camarosa cultivar were purchased from a local market in La Rochelle (France). The strawberries were manually cut parallel to the main axis into halves (for FD) or $1 \mathrm{~cm}$ slices (AFD and CMWD) of average $37 \pm 2 \mathrm{~mm}$ length, $18 \pm 1 \mathrm{~mm}$ width and $15 \pm 1 \mathrm{~mm}$ thickness with a stainless steel knife and weighted. The fresh samples had a moisture content of $11.66 \pm 1.42 \mathrm{~g} \mathrm{H}_{2} \mathrm{O} / \mathrm{g} \mathrm{db}$ (dry basis).

\subsubsection{Drying of the fresh strawberry}

$30.5 \pm 0.5 \mathrm{~g}$ strawberry slices were spread out evenly and subjected to three different drying methods based either on single continuous drying, namely (i) microwave drying "(CMWD)" at $20^{\circ} \mathrm{C}$; (ii) airflow drying "(AFD) at $50^{\circ} \mathrm{C}$ ” and (iii) freeze drying [5]. In this cases the pulse ratio $(\mathrm{PR})=\left(\mathrm{t}_{\text {on }}+\mathrm{t}_{\mathrm{off}}\right) / \mathrm{t}_{\text {on }}=1$.

\section{- $\quad$ Airflow drying (AFD)}

Strawberry slices were dried in a airflow dryer (Memmert: Universal Oven UNB Model 800) at $50{ }^{\circ} \mathrm{C}$ with an air flux of $1.2 \mathrm{~m} \mathrm{~s}^{-1}$. They were dried until attaining $0.10 \mathrm{~g} \mathrm{H}_{2} \mathrm{O} / \mathrm{g} \mathrm{db}$ (dry basis). These samples were recorded as AFD $50^{\circ} \mathrm{C}$.

\section{- $\quad$ Microwave drying (MWD)}

A domestic combined microwave oven with convection (Samsung, Model CE107F-S. Korea) with maximum output $900 \mathrm{~W}$ at $2450 \mathrm{MHz}$. In each experiment, strawberry slices of $30 \pm 0.5 \mathrm{~g}$ were placed in petri dish putting at the center of a glass turntable disc in the microwave chamber. Drying 
experiments were carried out with $100 \mathrm{~W}$ microwave power level at $20{ }^{\circ} \mathrm{C}$. The average value of effective MW power is about $62 \mathrm{~W}$.

\section{- $\quad$ Freeze Drying (FD)}

A freeze-drying equipment (RP2V model, Serail, France) was used for drying the strawberry halves. Three steps were used : external freezing $\left(2 \mathrm{~h}\right.$ at $\left.-20^{\circ} \mathrm{C}\right)$, sublimation $\left(-20{ }^{\circ} \mathrm{C}, 0.66 \mathrm{~Pa} / 12 \mathrm{~h}\right)$ and desorption $\left(25^{\circ} \mathrm{C}, 0.66 \mathrm{~Pa} / 12 \mathrm{~h}\right)[5]$.

\subsection{Pulsed Microwave drying (PMWD) of the rehydrated Swell dried SD strawberries}

The batch of 1-cm sliced strawberries was partially airflow dried (Memmert: Universal Oven UNB Model 800) at $50{ }^{\circ} \mathrm{C}$ and an air flux of $1.2 \mathrm{~m} / \mathrm{s}$ until $0.25 \mathrm{~g} \mathrm{H}_{2} \mathrm{O} / \mathrm{g} \mathrm{db}$. Afterwards, the partially airflow dried strawberries were textured by an optimized DIC treatment $(0.35 \mathrm{MPa}$ as saturated steam pressure for $10 \mathrm{~s}$ ) [5]. Finally, after DIC treatment, a traditional airflow drying at $50{ }^{\circ} \mathrm{C}$ was performed to get $0.08 \mathrm{~g} \mathrm{H}_{2} \mathrm{O} / \mathrm{g} \mathrm{db}$ as final water content. These samples were analyzed and recorded as control or SD.

$50 \mathrm{~g}$ of swell-dried slices of strawberries (Fragaria ananassa) placed in zipped airtight bags were rehydrated from 0.08 to $0.25 \mathrm{~g} \mathrm{H}_{2} \mathrm{O} / \mathrm{g} \mathrm{db}$ and stored in a cold chamber at $5{ }^{\circ} \mathrm{C}$ by $24 \mathrm{~h}$ to homogenize their water content. Approximately, $3.25 \pm 0.05 \mathrm{~g}$ of rehydrated SD expanded strawberry slices were spread out evenly and subjected to three different drying methods achieved from $\mathrm{W}=0.25$ to $0.1 \mathrm{~g}$ $\mathrm{H}_{2} \mathrm{O} / \mathrm{g}$ db based either on hybrid three stage drying process, namely (vi) airflow drying at $50{ }^{\circ} \mathrm{C}$; (v) Pulsed microwave drying "(PMWD)" at $20^{\circ} \mathrm{C}$ ambient temperature with active time ton maintained at $2 \mathrm{~s}$ at constant $100 \mathrm{~W}$, and three values of tempering time toff at 2, 5, and $10 \mathrm{~s}$, and (vi) a continuous operation of microwave was also performed (10 s ton and $20 \mathrm{~s}$ toff is the proper intermittent cycle of continuous use of domestic microwave oven at $100 \mathrm{~W})$.

From literature, initial know-how of LaSIE's research team, and preliminary experiments, two independent processing factors of PMWD process and their own respective ranges were selested; they were $t_{\text {on }}(2 \mathrm{~s})$, and $t_{\text {off }}(2-10 \mathrm{~s})$. The petri dish was removed from the oven and weighted at regular intervals at the end of power-off times during the drying period. By recording the successive times of $t_{\text {on }}$ and $t_{\text {off, }}$ we determined the moisture loss and drying rate during the pulsed microwave drying.

The measurements of moisture loss were performed by a gravimetric method at $60^{\circ} \mathrm{C}$ until weight stabilization, according to AOAC 930.04 [10], and expressed in $\mathrm{g} \mathrm{H}_{2} \mathrm{O} / \mathrm{g} \mathrm{db}$. After drying, each sample was photographed for assessing the sample visual quality. Drying Rate (DR) $\left(\mathrm{g} \mathrm{H}_{2} \mathrm{O} /(\mathrm{g} \mathrm{db} \min )\right.$ ) was calculated from the water contents dry basis values $\left(\mathrm{g} \mathrm{H}_{2} \mathrm{O} / \mathrm{g} \mathrm{db}\right) \mathrm{W}_{\mathrm{t}}$ and $\mathrm{W}_{\mathrm{t}+\mathrm{dt}}$ at time values of $\mathrm{t}$ and $\mathrm{t}+\mathrm{dt}$, respectively. $\mathrm{t}$ was the apparent drying time ( $\left.\mathrm{t}_{\mathrm{on}}+\mathrm{t}_{\mathrm{off}}\right)(\mathrm{s})$ :

$$
D R=\frac{W_{t+d t}-W_{t}}{d t}
$$

\subsection{Estimation of pressure within the superficial zone of the product during the first cycles}

By assuming that the holes of initial sample were full of water without any presence of air, the pressure inside the material matrix, expressed in $\mathrm{Pa}$, can be estimated versus the mass of generated vapor/pulsed cycle ( $\mathrm{g} /$ cycle) and the initial volume of water in the product $\left(\mathrm{m}^{3}\right)$, as follow: 


$$
\text { Internal vapor pressure }=\frac{m_{v} R T}{M_{\mathrm{H}_{2} \mathrm{O}} V_{w}}=\frac{\rho_{v} R T}{M_{\mathrm{H}_{2} \mathrm{O}}}
$$

Where, Мнго is the molar mass of water $(18 \mathrm{~g} / \mathrm{mol}), \mathrm{T}$ is the product temperature $(\mathrm{K}), \mathrm{R}$ is the universal gas constant, and $\mathrm{V}_{\mathrm{w}}$ is the water volume $\left(\mathrm{m}^{3}\right)$. The amount of water transformed into vapor per cycle should be correlated with the evaporation enthalpy $\Delta \mathrm{h}_{\text {vap: }}$ :

$$
m_{v}=\frac{0.62 * t_{\text {on }} * P}{\Delta h_{\text {vap }}}
$$

\section{Results and Discussion}

\subsection{Effect of PR on drying kinetics}
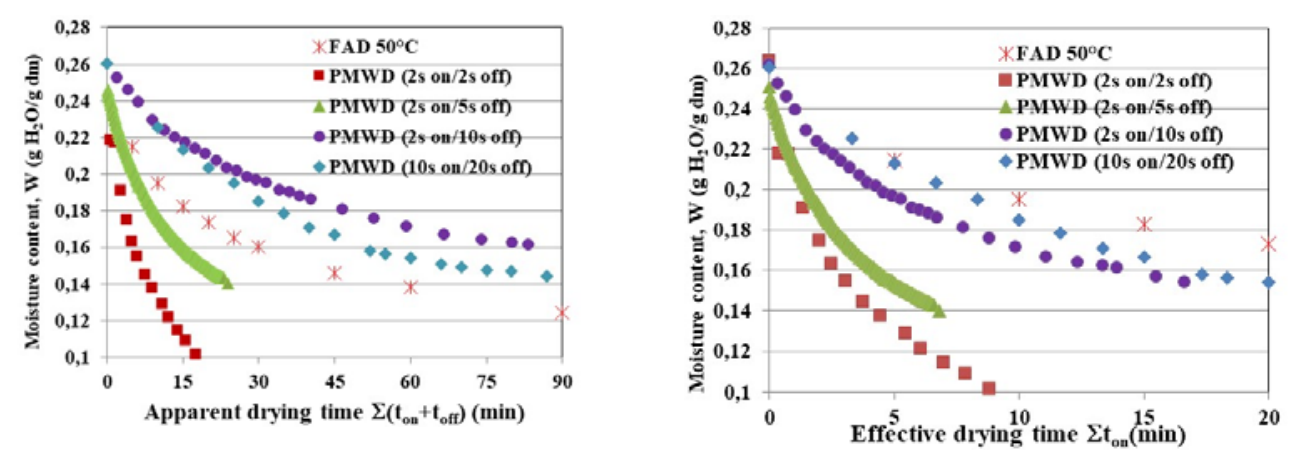

Fig. 1 The moisture content versus time curves for the AFD 50 ${ }^{\circ} \mathrm{C}, \mathrm{PMWD}(100 \mathrm{~W})$ of rehydrated SD strawberries (load of $3.25 \mathrm{~g}$ ) for apparent drying time $\Sigma\left(t_{o n}+t_{o f f}\right)$ and effective drying time $\Sigma_{\text {on }}$.

As shown in Figure 1, moisture content (W) continuously decreased vs drying time. To reach $\mathrm{W}=0.1 \mathrm{~g}$ $\mathrm{H}_{2} \mathrm{O} / \mathrm{g} \mathrm{db}$, PMWD (2 s ton/ 2-5 s toff) had a crucial acceleration of the drying process compared with AFD $50{ }^{\circ} \mathrm{C}$. At PMWD (2s ton $/ 2 \mathrm{~s}$ toff), W of about $0.1 \mathrm{~g} \mathrm{H}_{2} \mathrm{O} / \mathrm{g} \mathrm{db}$ was reached in $19.6 \mathrm{~min}$, which means only 9.8 min effective drying time. PMWD (10 s ton $/ 20 \mathrm{~s}$ toff) was lesser effective and resulted in poor product quality. This trend can be explained by a too high value of $t_{o n}=10 \mathrm{~s}$, which would result in increasing the internal heat with a generation of a dispersed deep case-hardening in different place within the volum. Higher tempering period results in an easier water balance within the sample, although without any modification of such a dispersed deep case hardening. By coupling an adequate low values of the active time $t_{o n}$, and high tempering period toff, greater availability of Darcy's transfer of vapor can occur. Nevertheless, an excess of toff normally results in negative impact in terms of kinetic.

\subsection{Effect of PR on drying rate versus apparent drying times}

For PMWD, a zigzag pattern of successive cycles of high peak/falling rate period was observed. This could be attributed to the redistribution of moisture and temperature during the tempering time provided by the thermal diffusion resulting in better water homogeneity and, thus, rapid moisture removal during the subsequent active microwave [11]. Thus, PMWD increase the pore pressure and a total pressure gradient between the internal and external media is established due to phase transitions and the thermodiffusion effect, thus leading to a highly effective Darcy-type vapor transfer. 


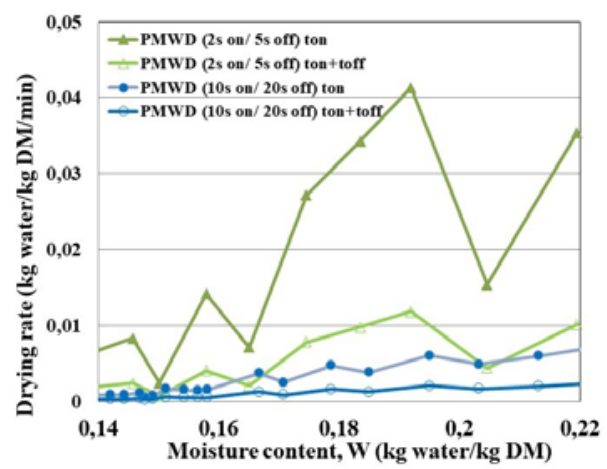

Fig. 2 Drying rate of PMWD operating parameters (effective drying time Iton or apparent drying time $\Sigma($ ton+toff) versus moisture content of rehydrated SD strawberries.

The drying rate of different pulsed microwave drying conditions was affected by tempering time $t_{\text {off }}$ (Fig 2). Generally, total drying rate has been as faster as $t_{\text {off }}$ decreased (shorter tempering time). This resulted in higher temperature and, thus, higher vapor pressure with, normally higher Darcy's vapor mass-transfer. The drying rate value calculated versus the effective drying time, was much higher. This result is crucial for industrial application and can be revealed through an adequate time and/or space intermittent repartition. Moreover, these phenomena did not strictly depend on PR. Thus, for approximatively the same $\mathrm{PR}=3$, PMWD ( $\left.2 \mathrm{st}_{\text {on }} / 5 \mathrm{~s} \mathrm{t}_{\text {off }}\right)$ were 5 times more accelerated than $\left(10 \mathrm{st}_{\mathrm{on}} / 20 \mathrm{st}_{\text {off }}\right)$.

\subsection{Quality attributes}

\subsubsection{Surface pressure during the first cycles}

Table 1 shows for ton=2s aninput heating energy substantially increasing with tempering time toff. Moreover, PMWD conducted at lower $t_{\text {off }}$ resulted in lower total effective drying time $\left(t_{o n}\right)$ and specific energy consumption compared to other intermittent combinations. This is because the higher the tempering time $t_{\mathrm{off}}$, the colder the surface because of superficial convection.

Table 1. Values of the total drying time, total ON drying time, specific consumed energy and estimated surface pressure for PMWD rehydrated swell-dried strawberries at different PR.

\begin{tabular}{ccccccc}
\hline $\mathbf{t}_{\text {on }}(\mathbf{s})$ & $\mathbf{t}_{\text {off }} \mathbf{( s )}$ & $\mathbf{P R}=\left(\mathbf{t}_{\mathbf{o n}}+\mathbf{t}_{\mathbf{~ o f f}}\right) / \mathbf{t}_{\text {on }}$ & $\mathbf{T}\left({ }^{\circ} \mathbf{C}\right)$ & $\Sigma\left(\mathbf{t}_{\text {on }}+\mathbf{t}_{\text {off }}\right)(\mathbf{s})$ & $\Sigma \mathbf{t}_{\text {on }}(\mathbf{s})$ & $\mathbf{P}(\mathbf{b a r})$ \\
\hline 2 & 2 & 2 & 20 & 1176 & 588 & 1.915 \\
$\mathbf{2}$ & $\mathbf{5}$ & $\mathbf{3 . 5}$ & 20 & 3185 & 910 & 1.919 \\
2 & 10 & 6 & 20 & 5988 & 998 & 1.888 \\
$\mathbf{1 0}$ & $\mathbf{2 0}$ & $\mathbf{3}$ & 20 & 10800 & 3600 & 5.203 \\
- & - & $1(\mathrm{AFD})$ & 50 & 16200 & 16200 & - \\
\hline
\end{tabular}

\subsubsection{Visual Attributes}

The first step of airflow drying AFD at $50{ }^{\circ} \mathrm{C}$ gave good visual attributes of the strawberry slices. Just after DIC-texturing, SD strawberry slices maintained the good natural visual color. On the other hand, 
it is wee-known that the freeze-dried strawberries lose their natural redness initial color. With SD slices as control samples, only PMWD ( $2 \mathrm{st}_{\text {on }} / 5 \mathrm{~s} \mathrm{t}_{\text {off }}$ ) gave no black/brown spots within the slice.

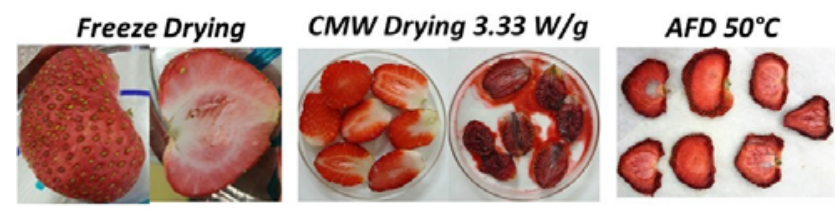

Drying of Rehydrated Swell Dried Strawberries

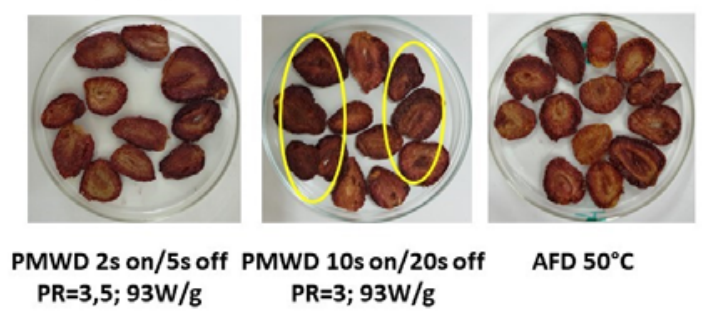

Fig. 2 Appearance of exemplary strawberries slices after continuous and PMWD modes.

Nevertheless, as soon as the PMWD active time is above a certain level ( $t_{\text {on }}>10 \mathrm{~s}$ ), many black spots emerged with less efficient drying kinetics. This can be attributed to deep "case hardening" delimiting areas with high internal tissue damage.

\section{Conclusions}

Based on both final product quality and operation performance, a multi-criteria optimization of Pulsed Microwave Drying PMWD was achieved. Microwave active time ton and tempering time toff were defined and optimized at $2 \mathrm{~s}$ and 2 to $5 \mathrm{~s}$, respectively. Although the microwave power was kept at 100 $\mathrm{W}$ for $3.25 \mathrm{~g}$ of strawberry slices, this MW distribution has prevented heat accumulation and put in equilibrium the internal water distribution, thus well generating vapor and its effective transfer towards the surrounding medium. These well-defined strawberries dried by AFD/DIC swell-drying and those of PMWD at $t_{o n}=2 \mathrm{~s}$ and $t_{\text {off }}=2 \mathrm{~s}$ exhibited the highest antioxidant activity and total phenol content.

Hence, the present three stage-intensified drying of AFD/DIC swell-drying/PMWD allowed the strawberry to effectively get the advantage of low internal temperature, thus acting against the paradoxical situation and remove the residual water from the porous matrix (after DIC) following Darcy's permeability as transfer way of residual vapor. With low energy consumption of DICexpansion and intermittent microwave, and since the drying kinetics was greatly increased, the total cost should become significantly lower than the simple Continuous MicroWave Drying.

\section{Nomenclature}

MWD Conventional Micro-Wave Drying

CMWD Continuous Microwave Drying

PMWD Pulsed Micro-Wave Drying

AFD Airflow Drying

DIC 
SD controlled texturing process

Swell-Drying, which combines a conventional (airflow) drying with

(PR) DIC-texturing.

Subscripts

pulse ratio $=\left(\mathrm{t}_{\text {on }}+\mathrm{t}_{\text {off }}\right) / \mathrm{t}_{\text {on }}=1$

ton

$t_{\text {off }}$

$\mathrm{T}_{\mathrm{i}}$ and $\mathrm{T}_{\mathrm{s}}$

$\mathrm{p}_{\mathrm{vi}}$ and $\mathrm{p}_{\mathrm{vs}}$

Active time, where both input MW heating energy and vapor mass- $\mathrm{S}$ transfer occure together

\section{References}

Tempering time, where there is no input MW heating energy, and vapor $\mathrm{s}$ mass-transfer mainly following Darcy's law, is assumed to be negligible. Temperature values at the core and the superficial zones, respectively $\quad{ }^{\circ} \mathrm{C}$ Absolute vapor pressures at the core and the superficial zones, $\mathrm{Pa}$ respectively

[1] 1. Giampieri, F.; Tulipani, S.; Alvarez-Suarez, J. M.; Quiles, J. L.; Mezzetti, B.; Battin, M. The strawberry: Composition, nutritional quality and impact on human health. Nutrition 2012, 28, 919.

[2] Doymaz, I. Airflow drying kinetics of strawberry. Chemical Engineering and Processing 2008, 47, 914-919.

[3] Amami, E.; Khezami, W.; Mezrigui, S.; Badwaik, L. S.; Bejar, A. K.; Perez C. T.; Kechaou, N. Effect of ultrasound-assisted osmotic dehydration pretreatment on the airflow drying of strawberry. Ultrasonics Sonochemistry 2017, 36, 286-300.

[4] Al Haddad, M.; Mounir, S.; Sobolik, V.; Allaf, K. Fruits \& Vegetables Drying Combining Hot Air, DIC Technology and Microwaves," International Journal of Food Engineering 2008, 4 (6), Article 9. DOI: 10.2202/1556-3758.1491.

[5] Maritza, A.M.; Sabah, M.; Anaberta, C.M.; Montejano-Gaitán, J.G.; Allaf, K..Comparative Study of Various Drying Processes at Physical and Chemical Properties of Strawberries (Fragariavarcamarosa). Procedia Engineering 2012, 42, 267-282.

[6] Tang, J.; Feng, H.; Lau, M. Microwave heating in food processing. Advances in Bioprocessing Engineering 2002, 1-43.

[7] . Zhang, M.; Tang, J.; Mujumdar, A.S.; Wang, S. Trends in microwave-related drying of fruits and vegetables. Trends in Food Science \& Technology 2006, 17, 524-534.

[8] Venkatachalapathy K.; Raghavan, G. S. V. Microwave drying of whole, sliced and pureed strawberries. Agricultural Engineering Journal 2000, 9, (1), 29-39.

[9] Gunasekaran, S. Grain drying using continuous and pulsed microwave energy.Drying Technology1990, 8 (5), 1039-1047.

[10] AOAC Official methods of analysis of the association of official analytical chemists. Moisture in dried fruits. (No. 930.04), Washington 1990.

[11] Gunasekaran, S. Pulsed microwave-vacuum drying of food materials. Drying Technology1999, 17(3), 395-412. 